\title{
Understanding the Biomechanical Properties of Skull Base Tissues Is Essential for the Future of Virtual Reality Endoscopic Sinus and Skull Base Surgery Simulators
}

\author{
Valentin Favier ${ }^{1,2}$ (D) $\cdot$ Patrice Gallet ${ }^{3} \cdot$ Gérard Subsol $^{4} \cdot$ Guillaume Captier $^{2}$ \\ ${ }^{I}$ Department of Otolaryngology-Head and Neck Surgery, Gui de Chauliac Hospital, University Hospital of Montpellier, Montpellier; \\ ${ }^{2}$ Aide à la Décision Médicale Personnalisée, Montpellier University, Montpellier; \\ ${ }^{3}$ Department of Otolaryngology-Head and Neck Surgery, Brabois Hospital, University Regional Hospital of Nancy, Lorraine University,
} Vandouvre-lès-Nancy;

${ }^{4}$ Montpellier Laboratory of Informatics, Robotics and Microelectonics (LIRMM), ICAR Team, French National Centre for Scientific Research (CNRS), Montpellier University, Montpellier, France

To the editor:

We would like to address the article titled "Virtual reality simulators for endoscopic sinus and skull base surgery: the present and future" by Kim et al. [1]. In the field of endoscopic sinus and skull base surgery (ESSBS), many virtual reality simulators (VRS) have been developed. The authors reviewed the current literature of these simulators and discussed the directions of future developments in a very interesting work. They focused on hardware, haptic devices, and software aspects. Consistently with the authors, we would like to emphasize the importance of haptic feedback development and to point out the current limitations of VRS in this field.

Haptic perception is defined as the combination of tactile perception and kinesthetic perception. In ESSBS, haptic perception is all the more important that tissues are not directly manipulated by the surgeon's hands under direct vision, but by specific tools with indirect monitoring through an endoscope. As a result, depth perception and haptic feedback are reduced while

\footnotetext{
- Received November 5,2018

Revised December 4, 2018

Accepted December 12, 2018

- Corresponding author: Valentin Favier

Department of Otolaryngology-Head and Neck Surgery, Gui de Chauliac Hospital, University Hospital of Montpellier, 80 Avenue Augustin Fliche, Montpellier 34000, France

Tel: +33-4-67-33-68-03, Fax: +33-4-67-33-68-08

E-mail: valentin favier@hotmail.com
}

hand-eye coordination is disturbed [2]. A low-fidelity haptic feedback on VRS could lead trainees to applying abnormal forces when using surgical tools in real practice [3]. Similar issues have been described in robotic surgery where haptic feedback is lacking [2]. This can be dangerous in clinical practice because trainees could damage important functional or vital structures (i.e., internal carotid artery, optic nerves, meninges, orbits...) and lead to patient's death or serious disability. Moreover, trainees are more comfortable and more accurate at characterizing tissues with simultaneous vision and haptic feedback than with visual feedback alone or haptic feedback alone [4].

Kim et al. [1] observed that most of ESBSS-VRS nowadays intend to provide haptic feedback. However, there are few data regarding the development and validation of haptic rendering. Indeed, to develop high-fidelity haptic tools, researchers need data on biomechanical properties of tissues, the most significant of which is the Young's modulus. Unfortunately, data are lacking regarding skull base mechanical properties [5]: indeed, the Young's modulus determination requires bending or tensile tests applied on multiple standardized formatted tissues samples. Yet the anatomy of the anterior skull base does not lend itself to standardized samples because of the frequent and large anatomic variations in bone thickness of the ethmoid and sphenoid paranasal sinuses, of the presence of multiple septa, and of its deep position within the head.

Realistic haptic feedback is crucial for the acquisition of surgi-

Copyright @ 2019 by Korean Society of Otorhinolaryngology-Head and Neck Surgery.

This is an open-access article distributed under the terms of the Creative Commons Attribution Non-Commercial License (http://creativecommons.org/licenses/by-nc/4.0)

which permits unrestricted non-commercial use, distribution, and reproduction in any medium, provided the original work is properly cited. 
cal skills. We are convinced that the future of high-fidelity ESSBS-VRS development lies in fundamental research on biomechanical properties of skull base tissues. Meanwhile, simulation on cadavers or on validated synthetic simulators seems to be the adequate solution for training curricula in ESSBS.

\section{CONFLICT OF INTEREST}

No potential conflict of interest relevant to this article was reported.

\section{ORCID}

Valentin Favier https://orcid.org/0000-0002-7999-951X

\section{REFERENCES}

1. Kim DH, Kim Y, Park JS, Kim SW. Virtual reality simulators for endoscopic sinus and skull base surgery: the present and future. Clin Exp Otorhinolaryngol. 2019 Feb;12(1):12-7.

2. Westebring-van der Putten EP, Goossens RH, Jakimowicz JJ, Dankelman J. Haptics in minimally invasive surgery: a review. Minim Invasive Ther Allied Technol. 2008;17(1):3-16.

3. FavierV, Zemiti N, Caravaca Mora O, Subsol G, Captier G, Lebrun R, et al. Geometric and mechanical evaluation of 3D-printing materials for skull base anatomical education and endoscopic surgery simulation: a first step to create reliable customized simulators. PLoS One. 2017 Dec;12(12):e0189486.

4. Tholey G, Desai JP, Castellanos AE. Force feedback plays a significant role in minimally invasive surgery: results and analysis. Ann Surg. 2005 Jan;241(1):102-9.

5. Waridel F, Monnier P,Agrifoglio A. Evaluation of the bone resistance of the sphenoid and ethmoid sinuses. Laryngoscope. 1997 Dec;107 (12 Pt 1):1667-70. 